\title{
La Libertad de Expresión en un Horizonte Multicultural
}

José Julio Fernández Rodríguez

Profesor Titular de Derecho Constitucional de la Universidad de Santiago de Compos. tela (España).

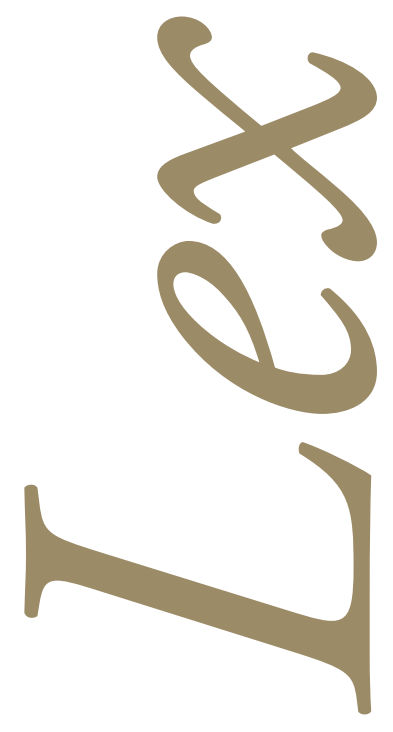




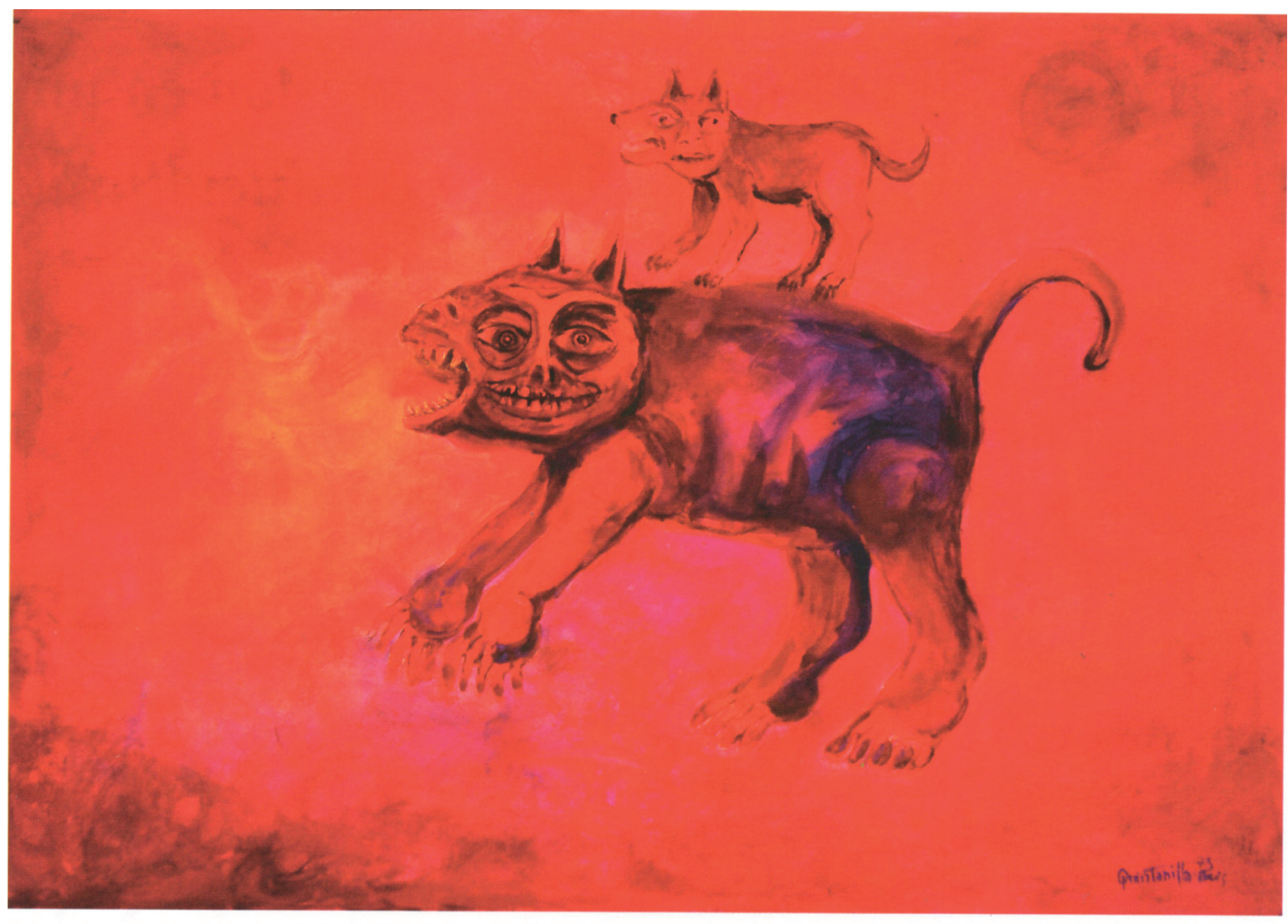

El perro loco y el perro curioso. Técnica mixta, $1973(75 \mathrm{~cm} . \mathrm{x} 106 \mathrm{~cm}$.) 
"Pas de liberté pour les énnemis de la libertée"

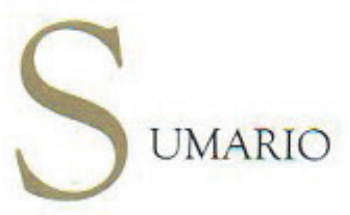

I- Introducción. II- Cultura y Multiculturalismo. III- Libertad de Expresión: Entre El Pasado y El Futuro. IV- Libertad de Expresión y Realidad Multicultural. V- Nuevas Perspectivas de ciertos limites a esta libertad. VI- Conclusiones.

\section{INTRODUCCIÓN}

1. Los profundos cambios de las últimas décadas que afectan a la sociedad en la que vivimos son un reto para la Ciencia del Derecho. Reto que se ve multiplicado en sus dimensiones e importancia cuando aparecen en escena derechos fundamentales. Los clivages explicativos de tales cambios son diversos y de dificil esquematización, pero siempre pasan, en un esfuerzo de sintesis, por el desarrollo tecnológico del mundo digital, por la complejidad de la sociedad internacional que nace del fin del a Guerra Fría y por el fenómeno de la globalización.

De este conjunto de transformaciones se deriva la realidad multicultural que está presente en muchos paises occidentales y que obliga a replantear el funcionamiento de diversas instituciones juridicas. Añadiendo mayor complejidad analitica a toda esta cuestión se encuentra el hecho de que semejante realidad multicultural puede resultar sumamente cambiante, tanto por si misma como por el contexto en el que se mueve. Sea como fuere, ello no debe producir especial alarma entre los juristas pues la finalidad primigenia del Derecho siempre ha sido la regulación de la vida en sociedad, y esta es por naturaleza cambiante. Por lo tanto, no estamos hablando de nada extraño sino de cumplir con esa exigencia básica de adaptación a la realidad social.

En esta tesitura, la libertad de expresión reclama reflexiones especificas que coadyuven a mantener operativos y eficaces sus mecanismos de garantía y que le permitan enfrentarse con éxito a las peculiares circunstancias de este siglo XXI. Con anterioridad ya habiamos realizado 
alguna aproximación bajo el prisma de tales intenciones ${ }^{1}$. Ahora, y de nuevo sobre la base de esta búsqueda de actualización de la libertad de expresión, ofrecemos al lector una aproximación al encuentro que se produce entre tal libertad y el escenario multicultural que cada vez se impone con más fuerza. La tradicional configuración de diversos derechos fundamentales, como el que ahora nos ocupa, se produjo en un contexto que poco o nada tiene que ver con el actual. Ello exige un proceso de adaptación y actualización con el objeto de no hacerles perder eficacia, respetando, eso sí, una continuidad dogmática que asegure que se reciban los logros que para la Historia de la humanidad supusieron tales derechos.

\section{CULTURA Y MULTICULTURALISMO}

2. Los estudios sobre el multiculturalismo son numerosos. Además, se hacen desde ramas del saber diferentes respondiendo a distintas motivaciones. No es este el momento ni el lugar de diseccionar las diversas aportaciones a este fenómeno sino de mantenerse en una posición más genérica. Por ello, entendemos por multiculturalismo la convivencia en una sociedad de diversas culturas. Convivencia, por lo tanto, y no enfrentamiento ni imposición ni choque, ideas que podrian derivarse de otras expresiones, como interculturalismo. En efecto, la terminologia en este terreno presenta especiales connotaciones, por lo que no resulta indiferente.

La cultura es un conjunto de referentes que permiten y facilitan a la persona relacionarse con su entorno. Es una invención humana que, en este sentido, implica la superación de elementos naturales. El asentamiento de una cultura la convierte en patrimonio de la comunidad en la que se establece transmitiéndose de generación en generación. Como afirma Quintana Cabanas, "una cultura es inicialmente un agregado de prejuicios" al subrayar ciertos aspectos de la realidad y suprimir otros. Ello implica una elaboración imperfecta dél conocimiento que se corrige de dos modos: "con el progreso de la experiencia, que rectifica los èrores, y con la confrontación continua con otras culturas, que le hacen de contrapeso" ${ }^{2}$. He aqui una de las ventajas del multiculturalismo.

La cultura se inserta en el Derecho generando relaciones y consecuencias bidireccionales. Las normas juridicas responden a determinado marco cultural y se tratan de asir al mismo para encontrar mayor realización práctica. El poder político también representará determinado tipo de cultura, que procurará usar para conseguir ventaja en el juego del ejercicio de su poder. De

1 Sobre las alteraciones que a la libertad de expresión plantea Internet puede verse nuestro libro Lo público y lo privado en Internet. Intimidad y libertad de expresión en la Red. México D.F.: Instituto de Investigaciones Juridicas, UNAM, 2004, pp. 31 y ss.

2 Quintana Cabanas, José Maria, "La intersección cultural en la educación europeista". En: Lopez-Barajas Zayas, Emilio (coord.). La Educación y la construcción de la Unión Europea, Madrid: Universidad Nacional de Educación a Distancia, 2000, p. 55. 
entre todas las normas juridicas es la Constitución la que presenta mayor incidencia cultural, al punto de convertirse, como advierte Häberle, en expresión de la autorrepresentación cultural de un pueblo ${ }^{3}$. A partir de aqui se puede diferenciar la expresión "cultura constitucional" de la de "Constitución cultural" ${ }^{4}$ con la intención de lograr mayor precisión terminológica.

Este esquema monocultural se abigarra y redimensiona con la realidad multicultural. La homogeneidad de la cultura constitucional de raiz liberal, que domina en Occidente y que le permite desarrollarse y asentarse, se somete hoy a ciertas dudas, algunas de las cuales, como veremos más abajo, hay que superar y rechazar. La libertad de expresión se construye en esta determinada cultura constitucional, la del clásico constitucionalismo de raigambre revolucionaria, que pasa hoy a ser un paradigma cultural relativizado con el multiculturalismo, si bien la pérdida de referentes tiene una dimensión mayor y, si cabe, más compleja al transitar también por posiciones nihilistas. El peligro de la no adaptación del nuevo entorno puede ser la pura y simple desintegración social. Por ello, la cultura constitucional ha de integrar un conjunto de culturas diferentes que permitan la convivencia en el contexto multicultural. En este sentido, Häberle maneja un concepto amplio de Constitución, que comprende las estructuras fundamentales de la sociedad plural ${ }^{5}$.

3. La globalización ha generado un efecto similar a una reducción de las distancias del planeta, lo que, unido a una mejora de las comunicaciones y de los transportes, permite la llegada de inmigrantes a las zonas más desarrolladas. Pero esta llegada se produce en ocasiones con unas características determinadas, diferentes a las de antaño, que les permiten mantener en gran parte su cultura y, por lo tanto, no diluirse en la cultura de la sociedad a la que llegan, a pesar de la dimensión homogeneizadora que imprime la globalización. Ello es especialmente predicable de Europa, que se ha convertido en el paraiso sonado en el imaginario colectivo de tantos lugares. En la vieja Europa existían, claro está, culturas diferentes, pero, salvo excepciones, no se superponian ya que permanecian en los márgenes que les marcaban las fronteras nacionales. El mosaico cultural que crece en Europa no solo es producto de la llegada de personas de otros continentes sino también a la trasmigración de los propios europeos, facilitada jurídicamente por las libertades que sostienen el pilar comunitario de la Unión Europea.

Esta situación no deja de tener una dimensión paradójica pues mientras la globalización, por un lado, impone elementos homogeneizadores de raiz occidental y liberal, por otro genera

\footnotetext{
HÄBERLE, Peter. Verfassungslehre als Kulturwissenschaft. Berlin: Dunker und Humblot, 1982, p. 19.

4 En opinión de Ruiz Miguel la expresión "cultura constitucional" nos acerca a la idea de que la Constitución "es un objeto o una creación de determinada cultura". En cambio, "Constitución cultural" se refiere a que "la cultura también es objeto o creación de una determinada Constitución" (Rutz Miguel, Carlos. "Libertad religiosa, Constitución y cultura". En: Cuestiones Constitucionales, núm. 10, México D. F, 2004, p. 232).

5 HÄberLe, Peter. El Estado constitucional. México D. F.: UNAM, 2001, p. 3-4.
} 
un proceso de reafirmación de lo local y de lo propio en ciertas colectividades que parecen querer protegerse frente al riesgo de imposición de pautas culturales ajenas. A pesar de la preponderancia de temas económicos, la globalización es también cultural e ideológica, con esta dimensión dual y paradójica a la que acabamos de aludir. Globalización cultural que es la que tiene mayores consecuencias estructurales y semánticas. Este refuerzo de lo local y esta actuación al unisono de lo global y de lo local permite acuñar el término "glocalización". Desde aquí se produce la superación de la cultura monolitica. En ese sentido, señala Mattelart que han surgido "nuevos enfoques sobre los vinculos que se establecen entre lo global y lo local, que rompen con la idea anterior de la fatalidad de la monocultura" ${ }^{\text {. }}$. Es por ello falsa la critica que algunos esgrimen contra la globalización al definirla como la exportación de la cultura occidental y el intento de uniformización y convergencia global. La realidad desmiente semejante crítica.

Una situación multicultural como la que estamos comentando genera un elevado número de problemas en diferentes órdenes, empezando por los derechos de las minorías ${ }^{7}$. La tolerancia propia de la democracia debe aplicarse también respecto a las otras culturas, cuyos aspectos positivos hay que valorar y cuyos elementos caracteristicos hemos de procurar entender superando prejuicios. Señala Hernando Sanz que se hace necesario "afrontar las diferencias debidas a la diversidad de forma constructiva y conciliadora" para que ello "nos lleve a la construcción social que nos proponemos" ${ }^{\text {. }}$. En definitiva, mostrarse con un espiritu abierto sin tener que renunciar a las propias convicciones. Aprender a vivir juntos es uno de los cuatro pilares del Programa de la UNESCO "Aprender para el siglo XXI", coordinado por Delors (los otros tres son aprender a conocer, aprender a actuar y aprender a ser).

4. El multiculturalismo abre una etapa diferente en el Estado Social como muestra de su permanente evolución. Señala Rolla que en los últimos años del siglo XX se produce una situación nueva en la que se reconoce el pluralismo y la diversidad al considerase a la persona no solo en su individualidad sino también como parte de un grupo o comunidad intermedia. "In tal modo -prosigue- emerge la caratterizzazione collettiva e storica della persona, il suo essere parte di un gruppo sociale più ampio e dotato di una spiccata identità, che le è fornita da elementi comuni, storicamente consolidati di natura étnica, lingüistica e culturale". Así las cosas, el reconocimien-

MattelarT, Armand. La mundialización de la comunicación. Barcelona: Paidos, 1998, p. 107.

Entre otros muchos, puede verse KrmLickA, Will. Ciudadania multicultural: una teoria liberal de los derechos de las minorias. Barcelona: Paidós, 2002. Del mismo autor, La Politica vernácula: nacionalismo, multiculturalismo y ciudadania, Paidós, Barcelona, 2003.

8 Hernando Sanz, Ma Ángeles. "La educación para la convivencia en la base de la construcción europea". En: López-Barajas Zayas, Emilio (coord.), La Educación y la construcción de la Unión Europea, Madrid: Universidad Nacional de Educación a Distancia, 2000, p. 207.

9 Rolla, Giancarlo. "La tutela costituzionale delle identità culturali: l'esperienza del Canada". En: Gambino, Silvio; Amirante, Carlo (coords.). Il Canada, un laboratorio costituzionale. Padua, CEDAM: 2000, p. 89. 
to, al lado de los derechos individuales, de los derechos conectados con la identidad cultural de los grupos es un elemento que caracteriza al constitucionalismo de las últimas décadas.

Al hilo de las consideraciones precedentes es comprensible la problemática que plantean los estados multiculturales, en donde hay que tratar de alcanzar un adecuado equilibrio entre los derechos individuales y los citados derechos relativos a la identidad cultural, entre los que se encuentran derechos territoriales en los que ahora no vamos a entrar pues no nos interesan en este trabajo. De lo que sí hay que dejar al menos constancia es de otro problema que ya entra en el objeto de estas páginas: la necesaria precisión de los instrumentos institucionales para garantizar la diversidad cultural y para estimular la integración de los diversos grupos. Estos equilibrios y ajustes de momento se han mostrado inestables.

\section{LIBERTAD DE EXPRESIÓN: ENTRE EL PASADO Y EL FUTURO}

5. La libertad de expresión es clave en cualquier sistema verdaderamente democrático al colaborar en la transparencia del mismo y en la conformación de una opinión pública libre, elemento básico de la inexcusable idea de pluralismo político. Como señala ROSENFELD la justificación de la libertad de comunicación se ha basado especialmente en tres cuestiones: su carácter esencial para el autogobierno democrático, la incidencia en el gradual descubrimiento de la verdad y el derecho del individuo a expresar su personalidad ${ }^{10}$. Son, por lo tanto, varios y diversos los puntos de vista que se pueden esgrimir para subrayar la relevancia de esta libertad, que con el paso del tiempo no ha encontrado mermado su papel vital en el constitucionalismo desde unos orígenes radicados en la defensa de la tolerancia religiosa. Su raigambre democrática pronto resultó incontestable asentándose en el núcleo del Estado liberal de Derecho. En efecto, la libre discusión, como diría MILTON, asegura que florezca la verdad sin la coacción y, por ello, sin la imposición unilateral de opiniones. Y como apuntaría John Stuart Mill, quien acalla esta libertad se arroga una infalibilidad carente de justificación, al tiempo que dificulta el medio de lograr la decisión más correcta y beneficiosa para el conjunto social. Es el mercado de la libre discusión de las distintas ideas y opiniones, en el que vencerá la mejor. Afirma Villaverde Menéndez que "las nociones libre discusión de las ideas y opinión pública tratan de resumir la función politica que en el Estado Liberal cumplió la libertad de opinión e imprenta”, función "que respondía a la fe ilustrada-liberal en la discusión libre y pública como fuente de racionalidad e instrucción públicas, dirigida al interés general, que era el interés único que debía guiar los asuntos de Estado" ". Asimismo, la libertad de expresión es una garantia de la imprescin-

10 Rosenfeld, Michel. "El nacimiento y la evolución de los derechos fundamentales en los Estados Unidos de América". Cuademos Constitucionales de la Cátedra Fadrique Furió Ceriol, núm. 18-19, Valencia, p. 82.

1 Villaverde Menéndez, Ignacio. "Introducción histórica a las libertades de información y expresión". En: VV. AA. La libertad de información y expresión. Madrid: Centro de Estudios Políticos y Constitucionales, 2002 , p. 25. 
dible crítica al poder público nacida como consecuencia del control al que debe ser sometido en el proceso democrático. A mayor abundamiento, esta libertad colabora en la formación de la ciudadania que, de este modo, podrá adoptar decisiones con mayor conocimiento de causa, lo que de nuevo incide en la linea de la selección de la mejor opción. Además de lo dicho, y citando de nuevo a Villaverde Menéndez, podemos reconocer otra función relevante de esta libertad como valor legitimador: "la estabilidad y seguridad necesarias para hacer posible la vida en sociedad exenta del uso privado de la coacción, que el Estado de Derecho debia garantizar, convirtiendo los enfrentamientos violentos entre diversas creencias y opiniones en disputas intelectuales en unos casos, o ante los jueces y tribunales en otros" ${ }^{\prime 2}$. En suma, en palabras del Tribunal Europeo de Derechos Humanos, la libertad de expresión es "uno de los principales fundamentos de una sociedad democrática y una de las condiciones más importantes para su progreso y desarrollo individual" (caso Handyside contra Reino Unido, de 7 de diciembre de 1976).

Los documentos revolucionarios ya hablaban de lo que hoy entendemos como libertad de expresión, que en aquel tiempo se llamaba libertad de opinión e imprenta. Es el caso de la Declaración de Derechos de Virginia de 1776, cuyo art. 12 establece que "la libertad de imprenta es uno de los más grandes baluartes de la libertad y solo un gobierno despótico puede restringirla"; o de la Declaración de Derechos del Hombre y del Ciudadano de 1789, en cuyo art. 11 se afirma que "la libre comunicación de pensamientos y opiniones es uno de los derechos más preciados del hombre; todo ciudadano puede, por tanto, hablar, escribir, imprimir libremente, excepto cuando deba responder del abuso de esa libertad en los casos determinados por la ley". En el siglo XX, a su vez, la Declaración Universal de Derechos Humanos establece en el art. 19 que "todo individuo tiene derecho a la libertad de opinión y de expresión; este derecho incluye el de no ser molestado a causa de sus opiniones, el de investigar y rećibir informaciones y opiniones, y el de difundirlas, sin limitación de fronteras, por cualquier medio de expresión". Otros reconocimientos también se producen en el Convenio Europeo para la Protección de los Derechos Humanos y de las Libertades Públicas (art. 10), en el Pacto Internacional de Derechos Civiles y Politicos (art. 19.2) o en la Convención Americana de Derechos Humanos (art. 13.1).

La doble vertiente, individual e institucional, de la libertad de expresión la convierten en un elemento necesario para el desarrollo social, que va más allá de la óptica de un clásico derecho subjetivo para colocarse en el terreno ya citado de la conformación de una opinión pública libre. En ella la "libertad" significa la no injerencia del Estado y lo "público" la posibilidad de acceso de todos. La dimensión institucional apunta con más fuerza el elemento democrático de la libertad de expresión.

12 Ibidem, p. 37. 
6. Las necesidades de precisión de las categorias juridicas llevaron a establecer una serie de diferencias que de una u otra forma tienen que ver con la libertad de expresión. Asi las cosas, y dejando de lado posiciones doctrinales diversas, podemos afirmar que la libertad de expresión es una manifestación externa de la libertad de pensamiento. Como deciamos en otro lugar, "de poco serviria esta libertad de pensamiento si no fuera posible difundir tal pensamiento"13. La libertad de pensamiento es una libertad genérica que posee un contenido complejo ${ }^{14}$, a la que a veces se alude como libertad de creencias (por ejemplo en el fundamento juridico 2 de la Sentencia del Tribunal Constitucional español 141/200015). En ella se incluirian de modo diferenciado la libertad ideológica y la libertad religiosa. De esta forma, la libertad religiosa es conceptualmente distinta a la libertad de expresión, aunque también aquella contiene una dimensión externa, que es la que permite a una persona manifestar su religión, como dice el art. 18 de la Declaración Universal de Derechos Humanos de 1948, "individual o colectivamente, tanto en público como en privado, por la enseñanza, la práctica, el culto y la observancia”. Otra forma de enfocar esta cuestión puede acabar de forma similar, que es la que nos interesa en este momento. Nos referimos a que si entendemos que la liberta genérica es la libertad ideológica, con una dimensión interna y no exteriorizada denominada libertad de pensamiento y una dimensión externa que comprendería manifestaciones diversas, la libertad de expresión sería también una de estas manifestaciones externas conceptualmente diferente a la libertad religiosa.

La situación, sin embargo, se ha complicado y no permite en ocasiones discernir con precisión entre las figuras involucradas. Ello es patente, a nuestro juicio, cuando, por ejemplo, una determinada visión del mundo no diferencia entre Religión, Política y Derecho, aplicando, por ello mismo, esquemas periclitados que el mundo occidental ya habia abandonado en el siglo II a. C. gracias al genio jurídico romano, abandono que se consolida con la definitiva superación de las estructuras mentales medievales. Estas visiones que confunden tales conceptos perpetúan en pleno siglo XXI, para perplejidad de la intelectualidad democrática, un modo de pensamiento retrógrado, disfuncional y agresivo con la libertad de la persona, cuyas causas y consecuencias no es ahora el momento de debatir, pese a su singular trascendencia. Lo que si queremos mostrar es que en ciertas ocasiones se va a hacer dificil deslindar entre la libertad religiosa y la libertad de expresión, lo que constituye un reflejo más de la necesidad de actualizar o reformular categorías para adaptarlas al nuevo contexto de la sociedad que nos envuelve.

FernÁNDez Rodríguez, José Julio. Lo público y lo privado en Internet. Intimidad y libertad de expresión en la Red, op. cit., p. 37.

14 Vid. Jean Rivero. Les libertés publiques, tomo II. Paris: Presses Universitaires de France, 1980, p. 130 y ss.

15 No obstante, esta sentencia no recoge la postura habitual de tal Tribunal, que suele emplear el binomio libertad ideológica-libertad religiosa sin referirse a otra libertad más genérica (por ejemplo, en la Sentencia 46/2001). Para ello se sigue una interpretación literal del art. 16 de la Constitución española, donde solo se habla de libertad ideológica y de libertad religiosa y de culto. 


\section{LIBERTAD DE EXPRESIÓN Y REALIDAD MULTICULTURAL}

7. Ante un contexto multicultural la libertad de expresión adquiere una dimensión y virtualidad práctica mayor que la que presenta en una realidad monocultural. En efecto, la libertad de expresión garantiza la manifestación de ideas y opiniones de las diversas culturas que se asientan en esa sociedad, en especial de las ideas minoritarias. El amplio objeto de la misma, que incluye tanto juicios de valor como pensamientos, creencias y opiniones (cualquier concepción intelectiva, en suma), y las posibilidades de usar cualquier medio o via, colaboran en esta virtualidad multicultural. El agere licere que le permite al individuo juega un rol ciertamente aprovechable en este nuevo contexto impidiendo el aislamiento social y enriqueciendo espiritualmente a la persona. Las dos grandes estrategias a emplear en una sociedad multicultural son el refuerzo de la diversidad y el avance por el camino de la integración. Aquella asegura el mosaico cultural, esta bebe del principio de igualdad. La libertad de expresión parece ser un elemento imprescindible que sirve a ambas estrategias aunque en principio se conecte con la primera, la tendente a conservar las especificidades culturales. Como recuerda Rolla, la dinamicidad de la cultura y de la sociedad excluye aplicaciones rígidas ya que no existe una estrategia que se pueda asumir en abstracto como modelo, "como paradigma per le politiche nei confronti dei dirittio dei gruppi alla loro identità storica e culturale" 16 .

Así las cosas, la libertad de expresión se configura como un precioso instrumento para la convivencia pues atestigua la capacidad de vivir juntos y de aceptar y compartir otras visiones de la vida en sociedad. Es también por ello, siguiendo esta óptica pedagógica, una libertad que actúa de impulso de la educación para la convivencia, precisamente en un tiempo como el actual, en el que las muestras de intransigencia presentan rasgos de habitualidad. La libertad de expresión dará testimonio de la capacidad de diálogo de una sociedad multicultural y será un elemento que frene el ya aludido riesgo de desintegración social anudado a la pérdida de homogeneidad de los referentes. La visión tradicional del pluralismo no será suficiente para satisfacer las exigencias de la sociedad multicultural y requerirá el apoyo de elementos nuevos y dinámicos, como lo es este entendimiento de la libertad de expresión, que permitan aportar garantías a los grupos.

En el pasado, el reconocimiento de la libertad de pensamiento y de la libertad de expresión no había roto la homogeneidad cultural sobre la que se asentaban ambas libertades. Ahora la heterogeneidad procede de causas en gran parte de naturaleza no juridica. La sociedad en cambio que nos circunda tiene el rasgo del pluralismo, un pluralismo novedoso que se encuentra en niveles muy diferentes de la continua metamorfosis de la aldea global. La verdadera democracia

16 Rolla, Giancarlo. "La tutela costituzionale delle identità culturali: l'esperienza del Canada". En: GambinO, Silvio; Amirante, Carlo (coords.). Il Canada, un laboratorio costituzionale. Op. cit., p. 100. 
sólo puede existir en cuanto democracia pluralista que, como tal, excluye proyectos totalitarios que impongan una única verdad. Las sociedades pluralistas actuales, indica Zagrebelsky, "asignan a la Constitución no la tarea de establecer directamente un proyecto predeterminado de vida en común, sino de realizar las condiciones de posibilidad de la misma"17. En efecto, la Constitución abierta ofrece un abanico de opciones reflejo del compromiso de posibilidades que implica. Es en esta linea donde el citado autor ofrece su concepto de derecho "dúctil" ("mite" en el original italiano) para defender "la coexistencia de valores y principios sobre la que hoy debe basarse necesariamente una Constitución", lo que "exige que cada uno de tales valores y principios se asuma con carácter no absoluto, compatible con aquellos otros con los que debe convivir", aunque sí será absoluto "el metavalor que se expresa en el doble imperativo de los valores (en lo tocante al aspecto sustancial) y la lealtad en su enfrentamiento (en lo referente a su aspecto procedimental)" ${ }^{18}$. Como vemos, esta autor coincide con nuestra posición de un núcleo democrático inquebrantable, sobre la que volveremos más abajo. De este pensamiento posibilista también se hace eco Häberle, que lo tilda de "pensamiento pluralista de las alternativas" (pluralistisches Alternativendenken), que se diferencia del pensamiento de la necesidad (el Derecho como medio para conseguir un fin) y del pensamiento de la realidad (concreción de la situación existente) ${ }^{19}$. De esta cultura del pluralismo emana la tolerancia, rasgo que debe transitar el Derecho Constitucional del siglo XXI y que es una forma diferente de enfocar el pluralismo.

En la correcta implementación de este propósito de hacer de la libertad de expresión un instrumento de integración multicultural, parece conveniente incidir en una visión global del proceso comunicativo, que englobe también al emisor y al receptor, y que no se circunscriba al mensaje, como le suele suceder a la mayoria de aproximaciones que se realizan a la libertad de expresión. Semejante visión global del proceso comunicativo ayudará a que dicha libertad se adapte mejor al contexto multicultural.

Asimismo, la libertad de expresión al servicio dẹl multiculturalismo permite avanzar por la senda de la Constitución abierta. El Derecho Constitucional del presente y del futuro no es el Derecho Constitucional de la Constitución dirigente sino de la Constitución abierta. La idea de Constitución dirigente, que procede de Gomes Canotilho ${ }^{20}$, alude a un programa de actuación futura que tiene que ser llevado a cabo por los poderes constituidos para, así, llegar a una sociedad más avanzada bajo la inspiración del principio de igualdad material. Semejante

Zagrebelsky, Gustavo. El derecho dúctil, Madrid, Trotta, 1995, p. 13.

15 Idem, p. 14.

19 HäBERLE, Perer. Die Verfassung des Pluralismus. Königstein, Arhenäum, 1980, pp. 1 y ss.

20 Gomes Canottlho, José Joaquim, Constituição dirigente e vinculaçáo do legislador. Coimbra: Coimbra Editora, 1982. La evolución de su pensamiento sobre este tema puede verse en "iRevisar la/o romper con la Constitución dirigente?". Revista Española de Derecho Constitucional, nủm. 43, 1995, pp. 9 y ss. 
planificación supone elevar la importancia de la estatalidad y reducir el margen de maniobra de los poderes públicos, si bien se impulsa su acción, aunque por sendas prefijadas. De esta forma, el Derecho Constitucional es un Derecho no dispositivo, por lo que "não há âmbito ou liberdade de confromação do legislador contra as normas constitucionais nem discricionariedade na não actuação de lei fundamental"21. Frente a la Constitución dirigente se sitúa la Constitución abierta, cuya construcción ha venido, en gran parte, de la pluma de Häberle y de su "teoria de la Constitución sin Derecho Natural" ${ }^{22}$ y de Hesse ${ }^{23}$, pero también puede ser enmarcada en una concreta idea de antropologia. Afirmar ese carácter abierto de un documento constitucional significa configurar un sistema que permita el acceso de todos al proceso politico y a los instrumentos de cambio politico. A ello coadyuva la libertad de expresión, máxime cuando esa sociedad presenta un carácter multicultural. De esta forma, se dota de mayor capacidad de movimientos a los poderes públicos a la hora de diseñar las politicas a seguir gracias a la flexibilidad del sistema. Se establecen cláusulas en el Texto Básico que contiene objetivos alcanzables por medio de diversas vías e instrumentos, a los cuales se alude globalmente. Gracias a esa globalidad, que no supone indefinición, se pueden realizar interpretaciones diferentes a lo largo del tiempo, con lo que se trata de ajustarse con mayor éxito a la realidad social y, de esa manera, cumplir con mejor fortuna las funciones a las que sirve la Ley Fundamental. Tendrían cabida en el sistema una variada gama de actos convirtiéndose el texto constitucional en la Constitución de una sociedad abierta y de un Derecho Constitucional que responde a los retos de la modernidad. Sin embargo, y como vamos a ver en el epigrafe siguiente, hay elementos que no deben permanecer abiertos, lo que supone traer a colación el tema de los límites de la libertad de expresión. Es decir, que no se puede aceptar un rotundo relativismo formal sino que la noción de Constitución abierta es perfectamente compatible con una comprensión material de la misma y con el aporte axiológico que esta conlleva y que da pábulo a las estructuras de la sociedad plural. En este sentido, la Constitución ejemplifica lo que Hart ha dado en llamar la "textura abierta del Derecho"24.

\section{NUEVAS PERSPECTIVAS DE CIERTOS LÍMITES A ESTA LIBERTAD}

8. Llegados aqui nos topamos con el núcleo básico de las reflexiones que estamos efectuando: ¿la nueva realidad multicultural requiere una reformulación de ciertos limites de la libertad de expresión? No se trata de abordar la abigarrada y compleja problemática de los límites a la libertad de expresión ni de categorizar tipos entre ellos (limites con una dimensión "pública" y

21 Ibidem, p. 63.

22 HäвERLE, Peter. Verfassung als öffentlicher Prozess. Materialen zu einer Verfassungstheorie der offenen Gesellschaft, Berlin, 1978; idem, Die Verfassung des Pluralismus, op. cit.

23 Hesse, Konrad. Grundzüge des Verfassungsrechts der Bundesrepublik Deutschland, 20 a ed., Heidelberg, C. F. Müller, 1995.

24 Hart, H. L. A. El concepto de Derecho. Buenos Aires, 1961, p. 159. 
limites de tipo "civil" o "privado", como el honor o la propiedad), sino de proporcionar algunas reflexiones sobre determinados limites que pueden verse afectados por una sociedad multicultural. En este sentido, parece que son los límites con mayor dimensión "pública" sobre los que hay que reflexionar, aunque tradicionalmente la mayor atención se les prestó a los límites "civiles" o "privados". La cuestión de fondo, en sus líneas esenciales, es una vieja conocida del Deıecho Constitucional. Se trata de determinar hasta qué punto son admisibles los grupos y las manifestaciones antisistema, lo que en el caso que ahora nos ocupa se concreta en determinar en qué medida deben protegerse o perseguirse opiniones que ponen en peligro al propio sistema o que contradicen elementos nucleares del mismo. Ello resulta especialmente predicable en un Estado democrático, en el que la muestra de pluralismo que supondría la admisibilidad de tales opiniones podria convertirse en el germen de su disolución.

9. Los problemas de otra cultura política no democrática que se dan cita en una realidad multicultural son de amplio calado, mucho mayor que el que algunos quieren transmitir. Los origenes históricos de la democracia, como apunta JIMENA QUESADA, "son incontestablemente occidentales" ${ }^{25}$. El Tratado de la Unión Europea, en su Preámbulo, confirma su adhesión "a los principios de libertad, democracia y respeto de los derechos humanos y de las libertades fundamentales y del Estado de Derecho", principios a los que se vuelve a referirse en su art. 6.

Frente a esto, y como es sabido, otras culturas no occidentales preconizan la instauración de sistemas políticos no regidos por el principio democrático. Aceptar esta situación dentro de las fronteras de un Estado democrático puede dar lugar a que la propia libertad concedida por la democracia sirva para destruirla. El Estado Liberal decimonónico ya había instaurado el castigo, con base en el principio de igualdad y a través de las leyes de sedición, de las opiniones contrarias a sus fundamentos. No obstante, la actual situación de multiculturalismo imprime una visión nueva a este problema.

El objetivo final en este sentido debe ser la búsqueda de una única cultura politica planetaria: la democrática. Por lo tanto, y desde este punto de vista, no debería haber multiculturalismo en lo político puesto que sólo es admisible la cultura política democrática. Sería la persecución de un ideal que hoy parece utópico pero que, a pesar de ello, estimamos que hay que defender. Este cosmopolitismo democrático no supone un empobrecimiento ni un reduccionismo ya que debe presentar unos perfiles un tanto amplios que permitan englobar opciones diversas, tal y como que veiamos antes al referirnos a la Constitución abierta. Lo que si contiene la cultura democrática es un núcleo básico irrenunciable basado en las ideas de control de poder, participación y pluralismo. Como la democracia todavía no ha se ha impuesto en diversos lugares y en distintas corrientes de pensamiento es preciso mantener la defensa de los elementos esenciales del orden

25 Jimena Quesada, Luis. La Europa Social y Democrática de Derecho, Madrid, Dykinson, 1997, p. 141. 
democrático como un límite para la libertad de expresión cuando el riesgo para el sistema es real y efectivo. Este limite adquiere una nueva dimensión con el multiculturalismo en tanto en cuanto traslada el problema al interior de los propios Estados democráticos. En una situación de normalidad la libertad de expresión sí puede admitir, y de hecho sucede, elementos antidemocráticos. Lo que no puede cubrir es manifestaciones de este tipo que se conviertan en un verdadero peligro para la democracia por las peculiares circunstancias que está viviendo la sociedad de que se trate ${ }^{26}$. La situación es, en cierto modo, paradójica pero trata de controlar las peligrosas consecuencias que para la supervivencia del orden democrático tendria otra manera de resolverla.

No creemos necesario en los tiempos que corren acudir a las formulaciones propias de la democracia militante o beligerante (que sirvieron en Alemania, por ejemplo, para basar declaraciones de inconstitucionalidad de partidos antisistema ${ }^{27}$ ) con el objeto de reforzar las afirmaciones precedentes. El propio Tribunal Europeo de Derechos Humanos analizó en varias sentencias la adecuación del comportamiento de funcionarios al orden constitucional y democrático interno alemán (caso Kosiek, de 28 de agosto de 1986, caso Glasenapp, de la misma fecha), considerando procedente la ingerencia de la autoridad pública consistente en la revocación del puesto de funcionario ${ }^{28}$. Ninguno de estos supuestos tiene un matiz multicultural sino estrictamente político e ideológico, pero demuestran que el mecanismo defensivo del sistema democrático frente a antidemócratas generó ya en el pasado consecuencias concretas. La construcción de las tesis propias de la democracia militante procede de un contexto diferente al actual, que obliga a reformularlas de manera importante. La República Federal Alemana de los años 70 del pasado siglo poco tiene que ver con la de la actualidad, superada, entre otras cosas, la lógica de la bipolaridad y de la Guerra Fría. Como afirma plásticamente Denninger, "se sabía dónde estaba el enemigo y cuál era su nombre" ${ }^{29}$. Por ello esta autor alemán argumenta que las nuevas circunstancias politicas y sociales no pueden dejar intactos los institutos de la democracia militante y su autodefinición. Entre los fenómenos que la afectan indica el "encontrar respuestas apropiadas a los nuevos retos, surgidos con la apertura de las fronteras intraeuropeas (...), con crecientes olas de migración e inmigración, la convivencia en pluralidad multicultural y la importación de conflictos politico-culturales-religiosos externos" ${ }^{130}$.

26 No obstante, en diversos ordenamientos ciertas manifestaciones antidemocráticas no se admiten aunque no supongan un peligro real para el sistema democrático. De ejemplo puede servir el racismo.

27 En 1952 del en 1952 del Partido Socialista del Reich (BverfGE, 2, 1) y en 1956 del Partido Comunista (BverfGE, $5,85)$.

28 Sin embargo, en un asunto similar y posterior, el Tribunal resolvió en sentido contrario (caso Vogt, de 26 de septiembre de 1995). Vid., JimENA QUESADA, Luis. "La posición constitucional de Alemania en al contexto europeo: revisión del concepto de democracia beligerante". Cuademos Constitucionales de la Cátedra Fadrique Furió Ceriol, núms. 14/15, Valencia, 1996.

29 Denninger, Erardo, "Democracia militante y defensa de la Constitución". En: VV. AA., Manual de Derecho Constitucional. Madrid: Marcial Pons-Instituto Vasco de Administración Pública, 1996, p. 446.

30. Idem, p. 447. 
10. Los problemas de otras culturas agresivas con los derechos fundamentales deben ser afrontados desde la única vertiente posible: la de la defensa y garantía de tales derechos, emanados de la misma dignidad de la persona. Por ello, la libertad de expresión no puede ser un baluarte defensivo en el que se escuden los violadores de los derechos insitos a la persona, derechos internacional y constitucionalmente reconocidos. Por desgracia, el objetivo de generalización y universalización de los derechos fundamentales todavía se halla lejos de ser conseguido siendo todavía muchos los que luchan contra tal fin.

Hablábamos antes de globalización, un fenómeno que, al margen de los elementos negativos que atesora, ha servido para expandir la cultura de la libertad más allá de los lugares donde históricamente se ubicaba. De manera paralela a este proceso se ha extendido por todo el planeta una dosis mayor de concienciación ante los problemas que afectan al mismo, la sensación de corresponsabilidad en su tratamiento y el avance en la educación bajo unos valores que, aunque sean preponderantemente occidentales, son más respetuosos con los derechos fundamentales. No estamos hablando de imposición de unas civilizaciones sobre otras sino de tener clara la prelación de los intereses en juego. Se alude, por ello, a la creación de una conciencia universal a través de la "consecución de unos valores y el establecimiento de unos mínimos parámetros, comúnmente aceptados, que permitan a todos los hombres sentirse por igual ciudadanos del mundo, con los mismos derechos y parejas obligaciones" 31 . La libertad de expresión tiene que servir a este propósito de la expansión de la cultura de los derechos humanos y no convertirse en un obstáculo a su implantación. El avance por el camino de la globalización que trate de proteger la autonomía y la diversidad tiene que producirse necesariamente sobre la base de un sustrato axiológico que considere inaceptables las situaciones agresivas con la dignidad de la persona y que asuma como inquebrantable su defensa. Esto no es imposición cultural sino justicia. Sentencia Denninger que "a fin de contrarrestar el peligro de una involución antipluralista y de un endurecimiento del consenso fundamental, lo mejor que cabe hacer es cobrar conciencia de que las libertades pertenecen al núcleo esencial" del consenso en torno al orden fundamental libre y democrático ${ }^{32}$.

En fin, no se pueden tolerar declaraciones contrarias a los derechos fundamentales, lo que constituirá un limite para la libertad de expresión. Parece que, tras años de titubeos y dudas, los poderes públicos de algunos paises democráticos ya empiezan a asumir esta afirmación y anudarle consecuencias. En España y Francia, por ejemplo, en los últimos meses se ha castigado o expulsado a responsables religiosos musulmanes por defender en sus manifestaciones y "enseñanzas" el "derecho" del hombre a pegarle a su(s) mujer(es). La respuesta social a esas medidas

1 Cebrian, Juan Luis. La Red, Taurus, Madrid, 1998, p. 192.

32 Denninger, Erardo. "Democracia militante y defensa de la Constitución". En: VV. AA. Manual de Derecho Constitucional, op. cit., p. 484. 
de castigo está siendo positiva. Es el caso de la expulsión de Francia, el 21 de abril de 2004, del imam Abdelkader Bouziane, que ejercía en una mezquita en Venissieux, a las afueras de Lyon, después de la polémica surgida por su entrevista a un semanario en la cual defendia que un marido podia pegar a su esposa. Esta persona, durante una entrevista que concedió a la revista Lyon Mag, aconsejaba incluso pegar a las mujeres "no en cualquier parte" sino "en los brazos y las piernas". En su opinión, el Corán legitima la violencia con la mujer, e incluso pegarle fuerte "para que tenga miedo" y sepa que no debe hacer algo la vez siguiente. Es España, a su vez, en enero de 2004 se condenó al imam de Fuengilrola, Mohamed Kamal Mustafá, a un año y tres meses de prisión por un delito de provocación a la violencia por razón de sexo que cometió al escribir un libro en el que aconsejaba cómo pegar a las mujeres sin dejar rastro. Dicho libro se publicó en Barcelona en 1997. Esta es la primera vez en España que se aplica este delito en un caso de discriminación sexual. En la sentencia condenatoria, dictada por el Juzgado de lo Penal núm. 3 de Barcelona, se dice que todo el libro del delincuente está precedido "por un tono de machismo obsoleto en algunos casos muy acentuado", que "vulnera abiertamente el principio de igualdad consagrado en la Constitución, promoviendo conductas de discriminación por razón de sexo intolerables y penalmente reprochables". El juez sostiene que decir frases como que en el hogar tiene que haber una autoridad suprema que debe ser el hombre o considerar que la mujer se ha convertido en un rival peligroso en pos de la victoria son "opiniones personales de Mohamed Kamal en su tarea de divulgación y constituyen mensajes contrarios a la igualdad de derechos y deberes entre los cónyuges". Según el juez, esto "supone negar la evidencia a la que la sociedad en la que viven los destinatarios del libro, que no es la del desierto de Arabia hace 14 siglos, se enfrenta diariamente ante actos de brutalidad contra las mujeres y que provoca un inaceptable reguero de victimas". Asimismo, afirma que "si otros autores de cualquier ideologia, convicción religiosa u origen cultural publican trabajos con idénticos mensajes habrá que pedir a los poderes públicos que extremen su celo en su persecución".

11. Los problemas de otras culturas que suponen un riesgo para la seguridad pública es el tercero de los límite al que vamos a aludir. Por desgracia, la realidad de los últimos tiempos evidencia desde el terror este peligro a través del despiadado rostro del terrorismo.

Distintos ordenamientos constitucionales y normas internacionales se han hecho eco del riesgo que para la seguridad supone cierto tipo de ideas, lo que se traduce en normas que expresamente introducen para la libertad de expresión el límite del orden público. Sirva como ejemplo la Constitución mexicana, cuyo art. 6 preceptúa que "la manifestación de las ideas no será objeto de ninguna inquisición judicial o administrativa, sino en el caso de que (...) perturbe el orden público" ${ }^{33}$. También la Declaración Universal de los Derechos Humanos, en el art. 29.2,

Diversos autores, como CARBONELL, han considerado que algunos limites que marca este art. 6 a la libertad de expresión son vagos y pueden ser interpretados de forma ambigua, por lo que aconsejan eliminarlos o redactarlos de forma que no dejen "espacios interpretativos que, en realidad, pudieran negar él ejercicio de la libertad 
alude al "orden público" al referirse a las limitaciones en el ejercicio de los derechos. Ello sólo es admisible que opere desde las exigencias de una sociedad democrática, a la que también alude la citada Declaración. En la misma línea se encuentra el art. 10.2 del Convenio Europeo para la Protección de los Derechos Humanos y de las Libertades Públicas al aludir a que el ejercicio de la libertad de expresión "podrá ser sometido a ciertas formalidades, condiciones, restricciones o sanciones previstas por la ley, que constituyan medidas necesarias, en una sociedad democrática, para la seguridad nacional (...) o la seguridad pública”.

Sin duda, las nociones de seguridad pública, seguridad nacional u orden público son especialmente delicadas por lo que deben recibir un tratamiento jurídico acorde con ello. Con relación a ello hay que tratar de catalogarlas como conceptos jurídicos indeterminados, no delimitables en toda su extensión a priori, pero sí cuando se producen las circunstancias que conducen a su aplicación. De lo que hay que huir es de ambigüedades que generen inseguridad jurídica. La operatividad de este límite a la libertad de expresión solo tendria que producirse cuando nos hallemos ante un auténtico peligro para el sistema dado que, como afirma Solozábal Echavarría, "en una democracia, basada en definitiva en una concepción optimista de la capacidad de discriminación del común de los ciudadanos de lo razonable sobre lo nocivo para los demás, debe tolerarse el mero revolucionarismo verbal" ${ }^{34}$. Es decir, la aplicación solo procederá en supuestos verdaderamente graves y con capacidad para generar consecuencias muy peligrosas. Hay que huir de conceptos vagos y flexibles como el de "la razón de Estado", para Meinecke "la máxima del obrar politico" y "la ley motora del Estado", que dice al político "lo que tiene que hacer, a fin de mantener al Estado sano y robusto" 35 .

12. En definitiva, los argumentos anteriores nos revelan que existen én esta problemática inevitables límites infranqueables ${ }^{36}$. El relativismo multicultural llevado a extremos es un riesgo, a pesar de la demagogia que a veces lo promueve. El multiculturalismo no puede entenderse en sentido absoluto ya que existe un núcleo irreductible que opera como limite intraspasable. Dicho núcleo está conformado por la democracia y por los derechos fundamentales, si es que éstos últimos no forman parte ya inescindible del concepto de aquélla. Además, la seguridad

de expresión" (CARBonell, Miguel. "Notas sobre la regulación constitucional de los medios electrónicos de comunicación”. Boletín Mexicano de Derecho Comparado, 2002, p. 345).

34 Solozabal Echavarria, Juan José. “Libertad de expresión y derecho a la información”. En: Aragon ReYez, Manuel (coord.). Temas básicos de Derecho Constitucional, tomo III. Madrid: Civitas, 2001, p. 172.

35 MeINECKE, Friedrich. La idea de la razón de Estado en la Edad Modema. Madrid: Centro de Estudios Constitucionales, 1983 , p. 3 .

36 Empleamos en este caso la categoria de "limite" para aludir a algo externo a un derecho fundamental. Esto significa que un límite afecta al contenido de un derecho, o sea, al espacio protegido del mismo, y no a su objeto, es decir, al espacio que cubre el derecho. Un concepto diferente sería el de limite inherente al derecho de que se trate y que, por lo tanto, afectaria a su objeto. 
pública, en un periodo de riesgos evidentes y extremos, tampoco puede perderse de vista en esta cuestión. El Derecho, como se ve, no puede ser neutral sino defensor de unos principios y valores esenciales, pocos pero existentes e inquebrantables. Su pequeño número permitirá la suficiente apertura constitucional y la rotación de alternativas en el marco de un sentimiento constitucional amparado en un texto básico construido con la lógica sistemática de un conjunto de articulaciones ${ }^{37}$. Estos pocos valores deben ser defendidos a ultranza por el Derecho Constitucional, que tiene que mostrar hoy en día una posición precavida ante el multiculturalismo para que el mismo no menoscabe la dignidad y el corpus de derechos fundamentales.

Lo dicho, sin embargo, debe entenderse en sus justos términos y no ser un arma arrojadiza a usar por quien planee reducir las dimensiones y las garantias de los derechos fundamentales sin razones que lo justifiquen, sobre todo cuando se alegan razones de seguridad pública. La aplicación de los limites a la libertad de expresión debe efectuarse dentro de la normalidad del sistema constitucional y rodearse, por ello, de las exigencias y requisitos propios del funcionamiento de los limites de los derechos fundamentales. La aproximación analitica a ello puede hacerse aplicando el método escalonado (Stufentheorie) que usan la jurisprudencia y doctrina alemanas en la determinación de la legitimidad de una intervención en un derecho fundamental. Este método consiste en ir analizando los diversos escalones que lo integran de manera tal que si el examen no pasa uno de ellos ya no se continúa el análisis. Llegar y superar con éxito el último de los escalones supone que la intervención en un derecho fundamental es legitima y, por ende, se encuentra justificada. Este método tiene tres fases: una, la determinación del ámbito normativo del derecho; dos, la fijación de la existencia real de una injerencia en el derecho; y tres, el estudio de la legitimidad de dicha injerencia. En esta última fase hay, a su vez, cinco escalones: el principio de reserva de ley, la generalidad de la misma, la reserva jurisdiccional, el principio de proporcionalidad en sentido amplio ${ }^{38}$ (que contiene tres subprincipios: el de idoneidad, el de necesidad y el de proporcionalidad en sentido estricto, más el presupuesto lógico de la finalidad perseguida) y el respeto al contenido esencial de los derechos fundamentales, si se entiende que ello es diferente a la proporcionalidad. El punto de partida de este proceder es la siguiente idea: la regla general es la vigencia del derecho fundamental de que se trate, mientras que la excepción sería el límite a dicho derecho.

Sea como fuere, al margen de las argumentaciones abstractas y teóricas que se pueden efectuar en todo tema relacionado con los limites a un derecho fundamental, siempre habrá que tener acudir al concreto caso que se plantea para solucionar adecuadamente el problema prácti-

37 Sobre las articulaciones constitucionales puede verse LuCAS VERDÚ, Pablo. Teoria General de las articulaciones constitucionales, Madrid: Dykinson, 1998.

38 El art. 52 de la Carta de Derechos Fundamentales de la Unión Europea establece que "sólo se podrán introducir limitaciones (a los derechos fundamentales), respetando el principio de proporcionalidad". 
co y real examinando las peculiares circunstancias que lo rodean. En este sentido, cabe recordar que el contexto cultural y social al que pertenezca la persona encargada de adoptar la decisión correspondiente influirá, a veces de manera poderosa, en la misma, lo que pone de manifiesto que la problemática de la multiculturalidad aparece en frentes diversos para añadir elementos de complejidad a los que inicialmente la circunscriben. El test de proporcionalidad, sin duda, está muy imbuido por la cultura en la que se desenvuelve el aplicador (lo proporcionado o desproporcionado lo es en función del ámbito social en el que se produce). Al margen de ello, y de nuevo desde una vertiente abstracta, los fines perseguidos por la aplicación de medidas restrictivas de la libertad de expresión en defensa de la democracia, de los derechos fundamentales y de la seguridad pública presentan singular relevancia, aunque resulten necesarias su justificación y concreción posteriores. Parece justificada (insisto: desde un punto de vista teórico y abstracto que habrá que terminar de dilucidar casuisticamente) la restricción de la libertad de expresión con base en el interés público que está detrás de la finalidad perseguida con esas tres limitaciones, interés que se impone, de este modo, al interés del titular del derecho.

13. Una cuestión diferente a la de los limites de un derecho fundamental sería la de su suspensión, que suele anudarse a estados excepcionales, que, como tales, solo se aplican en supuestos extremadamente graves. La suspensión de un derecho implica la cesación temporal de su existencia, aunque no ausente de garantías, cosa que no sucede, claro está, cuando opera un limite. La diversa regulación que existe en Derecho Comparado sobre estados excepcionales suele afectar a la libertad de expresión, aunque ahora no vamos a entrar en ello para no apartarnos de nuestro hilo argumental. También es cierto que hay casos importantes, al menos teóricamente, de suspensión de derechos fundamentales desligados de los estados excepcionales, como el contemplado en el art. 18 de la Ley Fundamental de Bonn, que se activa frente al empleo abusivo de derechos para atentar contra el orden fundamental libre y democrático. De esta forma, en Alemania quien abuse de la libertad de expresión para combatir dicho orden puede perderla a través de una declaración del Tribunal Constitucional federal. No obstante, nunca se ha producido una declaración de este tipo, aunque si hubo casos que estudió el Tribunal (BverfGE 11, 282; 38, 23).

\section{CONCLUSIONES}

14. La libertad de expresión se nos muestra como un útil instrumento para afrontar la creciente complejidad multicultural ayudando, en este sentido, a evitar el peligro de la desintegración social motivada por la falta de homogeneidad de los referentes. Esta visión de la libertad de expresión es coherente con la cultura del pluralismo que transita una sociedad abierta y de la que nace el rasgo de la tolerancia. 
La libertad de expresión es un elemento que sirve no solo a la estrategia que aparece en las sociedades multiculturales tendente al mantenimiento de la diversidad, sino también a aquélla otra que semeja contrapuesta a la anterior en tanto en cuanto busca la integración. Se revela, asi, como un preciado recurso con virtualidad a escala individual e institucional, por lo que debe recibir el adecuado tratamiento juridico que le dote de eficacia en el contexto multicultural de nuestra sociedad sin merma de su contenido.

15. El multiculturalismo tiene que cohonestarse con la defensa de la democracia y de los derechos fundamentales. Precisamente son los valores occidentales, construidos en lucha contra la intolerancia y contra el desprecio de la persona, los que más se acercan a un sistema respetuoso con la democracia y la libertad. No podemos admitir un relativismo cultural absoluto porque puede ser agresivo con ambas, esto es, con la democracia y la libertad. Ciertas manifestaciones culturales son contrarias a la dignidad de la persona, vulnerando por ello ese minimum irrenunciable, lo que debe originar, en ocasiones, la oportuna reacción por parte del poder público.

Estamos en tiempos dificiles, en los que la seguridad internacional está sometida a nuevos y dificiles desafios. Ante ello, por un lado, hay que huir de la tentación de reducir las garantias de los derechos en aras a un mal entendimiento del concepto de seguridad, y, por otro, hay que hacer una apuesta decidida por los valores democráticos con el objeto de frenar la expansión de la intolerancia. La libertad de expresión no puede usarse equivocadamente para dar pábulo a los enemigos de la libertad por lo que, dentro de la normalidad del Estado de Derecho, deben operar los limites a la misma basados en la defensa de los elementos esenciales del sistema constitucional: la democracia, los derechos fundamentales y la seguridad pública. La cláusula con la que abriamos este trabajo condensa tales ideas: "Pas de liberté pour les énnemis de la liberté". No obstante esta máxima propia de la democracia militante hay que adecuarla a los nuevos tiempos que marca este siglo XXI por el que transitamos y cohonestarla con el horizonte multicultural que enfilamos.

16. En definitiva, vivimos en un mundo de cambio que se extiende por todas las dimensiones del conocimiento humano. El Derecho Constitucional tiene que mostrarse ágil en sus respuestas para seguir disciplinando correctamente la realidad sociopolítica que está llamado a regir. El adecuado entendimiento de la interacción entre libertad de expresión y realidad multicultural responde a semejante desafio. 